
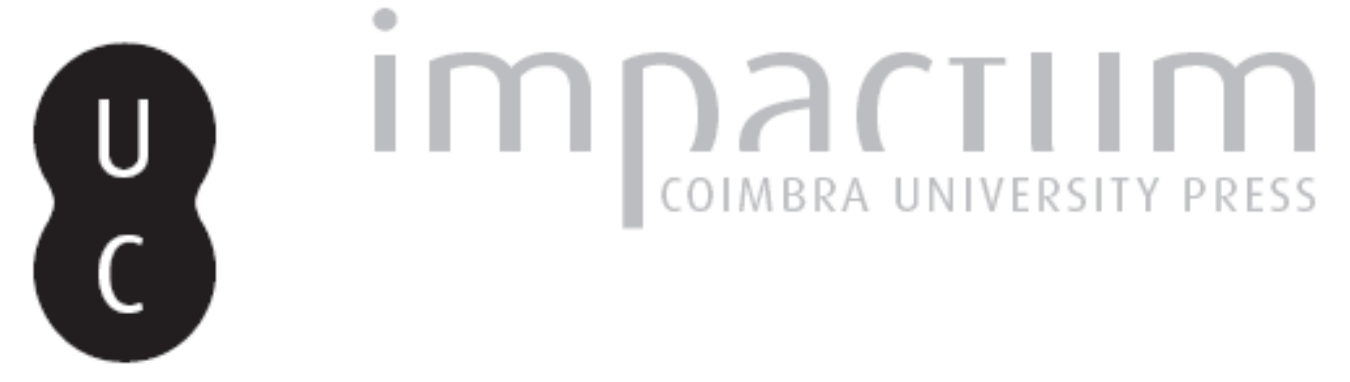

\title{
O fundamento da liberdade humana em Santo Tomás de Aquino
}

\section{Autor(es): $\quad$ Alves, Anderson Machado R.}
Publicado por: Universidade Católica de Petrópolis; Instituto Brasileiro de Informação em Ciência e Tecnologia

URL

persistente:

URI:http://hdl.handle.net/10316.2/33033

DOI:

DOI:http://dx.doi.org/10.14195/1984-6754_3-2_1

Accessed : $\quad$ 26-Apr-2023 15:47:44

A navegação consulta e descarregamento dos títulos inseridos nas Bibliotecas Digitais UC Digitalis, UC Pombalina e UC Impactum, pressupõem a aceitação plena e sem reservas dos Termos e Condições de Uso destas Bibliotecas Digitais, disponíveis em https://digitalis.uc.pt/pt-pt/termos.

Conforme exposto nos referidos Termos e Condições de Uso, o descarregamento de títulos de acesso restrito requer uma licença válida de autorização devendo o utilizador aceder ao(s) documento(s) a partir de um endereço de IP da instituição detentora da supramencionada licença.

Ao utilizador é apenas permitido o descarregamento para uso pessoal, pelo que o emprego do(s) título(s) descarregado(s) para outro fim, designadamente comercial, carece de autorização do respetivo autor ou editor da obra.

Na medida em que todas as obras da UC Digitalis se encontram protegidas pelo Código do Direito de Autor e Direitos Conexos e demais legislação aplicável, toda a cópia, parcial ou total, deste documento, nos casos em que é legalmente admitida, deverá conter ou fazer-se acompanhar por este aviso.

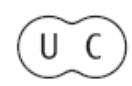



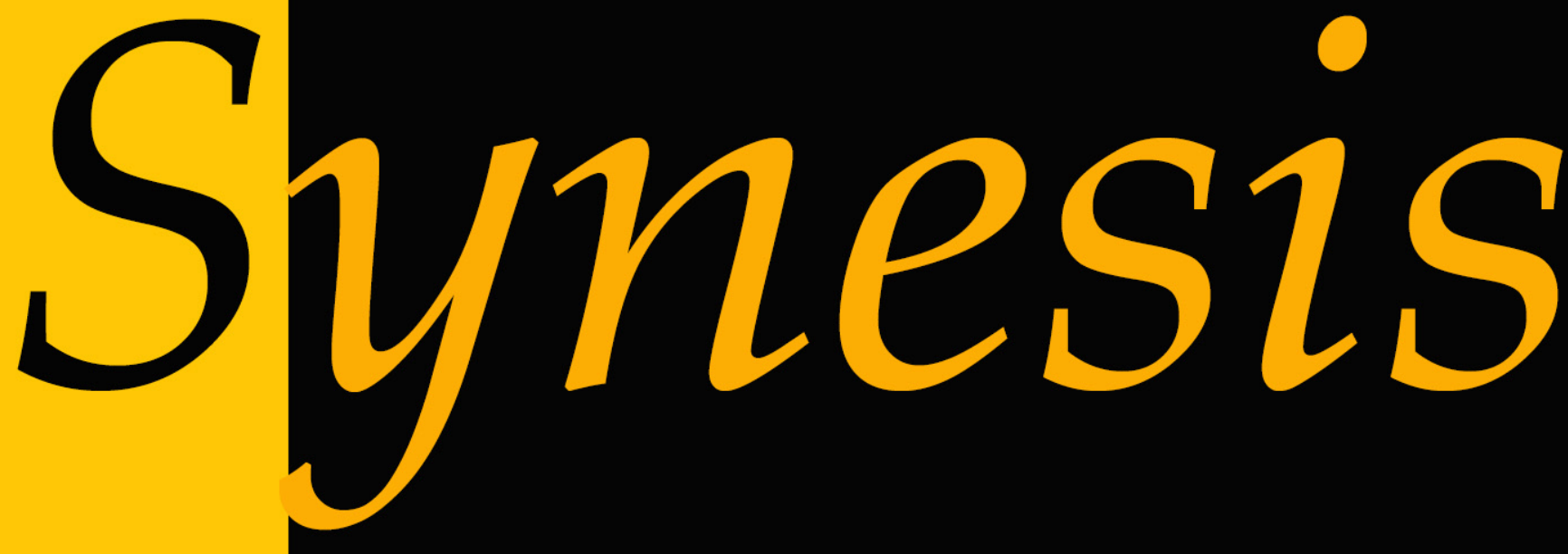

Revista do Centro de Teologia e Humanidades ISSN 1984-6754

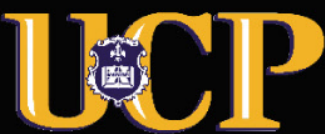




\section{O FUNDAMENTO DA LIBERDADE HUMANA EM SANTO TOMÁS DE AQUINO}

Anderson Machado R. Alves ${ }^{2}$

Resumo: Nesse trabalho expomos o fundamento da liberdade humana em Santo Tomás de Aquino: o ato de ser, que é o mesmo ato da alma humana que informa todas as potências e capacidades da pessoa. Tal ato de ser se reduz ao ato de ser divino. Deus, de fato, o causa livremente, com um ato de amor. Tal ato primeiro de Deus faz inerir no ser e na liberdade humana uma finalidade, uma direção ao fim último universal. Antes de apresentar e comentar os textos nos quais Santo Tomás trata explicitamente do assunto mostramos que a noçáo de liberdade é análoga, tanto na filosofia moderna, caracterizada por uma busca incessante pela liberdade, assim como em Santo Tomás de Aquino, uma vez que a liberdade humana se manifesta em diversas dimensóes da vida humana. Para Santo Tomás a liberdade é característica essencial dos seres racionais: de Deus, dos anjos e dos homens. E a liberdade humana apresenta três níveis: a liberdade de escolha (livre arbitrio), a liberdade fundamental e a liberdade moral. Tratamos esses níveis, com o intuito de mostrar a riqueza da análise tomista sobre esse tema, em diálogo com a filosofia moderna.

Palavras-chave: Liberdade humana; Antropologia; Tomás de Aquino.

Abstract: We expose the foundation of human freedom in Saint Thomas of Aquinas. For Aquinas the act of being is the same act of the human soul that informs all of the potencies and the human person's capacities. The act of a human being is reducible to the act of a divine being. Meaning, the divine being causes or creates the act of being human freely for an act of love. This first act of God makes inherit in human being's act a purpose, a direction to the universal last end. Before presenting and commenting on the texts which Saint Thomas deals explicitly with the matter of human freedom, we showed that the notion of freedom is similar to the idea of freedom found in modern philosophy, which is characterized by their shared incessant search for freedom. Saint Thomas holds that human freedom manifests itself in several dimensions of rational beings: of God, of the angels and of the men. Freedom exists in three levels: the choice freedom (free will), the fundamental freedom and the moral freedom. We treated those levels with the intention of showing the wealth of the Thomistic analysis on this theme.

Keywords: Human liberty; Antropology; Thomas Aquinas.

\footnotetext{
${ }^{1}$ Artigo recebido em 13/10/2011 e aprovado para publicação pelo Conselho Editorial em 02/12/2011.

2 Doutorando em filosofía pela Pontificia Università della Santa Croce (Roma). Email: amralves filo@yahoo.com.br.
} 


\section{Introduçáo}

Pode-se dizer que poucos assuntos são tão discutidos em filosofia quanto à liberdade humana. A filosofia moderna nasce como uma busca de liberdade, entendida como autonomia de vários bens e valores que formavam a sociedade antiga e medieval. Sendo assim, pode parecer a muitos que a afirmação do homem como ser livre foi a grande descoberta filosófica da modernidade.

Nesse trabalho apresentamos algumas noçóes de liberdade dada por alguns filósofos modernos, mostrando a polissemia dessa noção nessa época histórica. Mostramos que a partir de então a liberdade deixa de ser entendida desde seu fundamento metafísico, como radicada no ato de ser pessoal, e passa a ser afirmada somente a partir da consciência ou da experiência pessoal. Desse modo iniciou-se um processo que tende a ver a liberdade como mera autonomia, ou como indiferença diante da atratividade do bem, o que trouxe importantes conseqüências não só filosóficas, mas também sociais e políticas.

Com o intuito de dialogar com a filosofia moderna e contemporânea investigamos essa questão nas obras de Santo Tomás de Aquino, a fim de vislumbrar o fundamento último da liberdade humana. Ao longe dessas páginas vemos que o fundamento último da liberdade é o ato de ser pessoal, que é uma participação no ser divino e que informa todas as potências humanas. Afrontamos a relaçáo da liberdade humana com as potências mais altas da alma humana: a razão e a vontade, mostrando como a liberdade humana é sempre uma liberdade limitada, participada e, como todos os demais entes criados, provida de uma finalidade.

Fazemos uma releitura do Aquinate a partir da colaboração de filósofos contemporâneos, que procuraram penetrar a fundo no pensamento de Santo Tomás, assim como na filosofia moderna e contemporânea. Analisamos, pois, algumas colaborações da releitura feita por C. Fabro, C. Cardona e Ll. Clavell daquele grande autor medieval.

\section{A liberdade humana vista pela modernidade}


Um grande número de filósofos modernos afirmou com forças, e às vezes com exagero, a existência e o valor da liberdade humana. R. Descartes, por exemplo, disse que não há nada que nos é conhecido com maior evidencia do que a liberdade 3 . De modo semelhante, H. Bergson afirmou que "a liberdade é um fato e, entre os fatos que constatamos, não há nenhum que nos seja mais claro" ${ }^{4}$.

E, no auge da Ilustraçáo, I. Kant disse algo semelhante: a autonomia da vontade aparece como evidente diante da lei moral, pois o homem intui o dever moral e a possibilidade de transgredi-lo assim que toma consciência de ser livre 5 .

Desse modo, esses filósofos (e outros modernos) acentuaram algumas vezes a liberdade como algo evidente à consciência (ao cogito). Outros filósofos, no entanto, afirmaram a liberdade a partir de uma experiência humana básica: nossa vontade aparece sempre como indeterminada diante da possibilidade de fazermos escolhas. Para afirmar filosoficamente a liberdade humana, pois, a modernidade parte ou da consciência subjetiva da liberdade, ou da experiência, sem grandes indagações metafísicas.

Ainda podemos lembrar o filósofo e teólogo cristão R. Guardini, que muito refletiu sobre o tema da liberdade ${ }^{6}$. Afirmou que a consciência de ser livre é um conteúdo imediato da experiência humana e definia a essência da liberdade como auto pertença, no sentido em que o ato livre nasce em mim e é perfeitamente meu. É interessante notar que também Santo Agostinho e Santo Tomás de Aquino disseram que a auto pertença é um aspecto da liberdade humana ${ }^{7}$.

\footnotetext{
${ }^{3}$ DESCARTES, R. I principi della filosofia, Pars Prima, XLI, Torino: Bollati Boringhieri, 1992, p. 92. A tradução ao português das obras citadas nesse trabalho é sempre nossa.

${ }^{4}$ BERGSON, H. Essai sur les données immediates de la conscience, Édition du Centenaire, Paris: PUF, 1970, p. 145 .

${ }^{5}$ Cfr. KANT, I. Critica della ragione pratica, Prefazione, Milano: Rusconi, 1993, p. 39.

${ }^{6}$ GUARDINI, R. Persona e libertà. Saggi di fondazione della teoria pedagogica, Brescia: La Scuola, 1990, pp. 5859: "La libertà è autoappartenenza. Mi esperisco libero quando provo di appartenermi; quando provo che agendo dipendo da me stesso, che l'azione non transita attraverso di me e perciò spetta ad un'altra istanza, ma sorge in me, $e$ quindi è mia in quel senso peculiare, ed in essa sono io".

7 S. Th., I, q. 38, a. 1 ad 1: "Homo liber dicitur esse sui ipsius. Et hoc est quod Augustinus dicit, Super Ioan. (Tract. XXIX, super VII16) 'quid tam est quam tu?'”.
} 
Entretanto, deve-se notar que na modernidade a liberdade humana aparece com um grande número de significados, o que deu origem a grandes discussóes. Tende-se a acentuar nesse período a liberdade política, entendida como autonomia das autoridades até entáo constituídas, assim como há a tendência a ignorar o fundamento metafísico e antropológico da liberdade. Muitas vezes filósofos modernos e pós-modernos apresentam a liberdade como descoberta, ou mesmo como invenção da filosofia moderna. Isso pode parecer correto se nos referirmos às liberdades políticas e sociais surgidas naquele período, mas a liberdade humana enquanto tal é uma descoberta essencialmente cristã. Isso foi reconhecido inclusive por um dos maiores filósofos modernos, Hegel, em palavras extremamente esclarecedoras.

Inteiras partes do mundo, a África e o Oriente não tiveram jamais esta idéia; os gregos e os romanos, Platão e Aristóteles não a tiveram jamais. Esses sabiam, ao contrário, que o homem é realmente livre mediante o nascimento (como cidadão ateniense, espartano etc.) ou em virtude do caráter, da educação, mediante a filosofia (o sábio é livre, também quando é escravo e atado em correntes). Esta idéia veio ao mundo mediante o Cristianismo segundo o qual o indivíduo tem como tal um valor infinito, porque esse é objeto do amor de Deus, é determinado a ter com Deus como espírito a sua relação absoluta, a ter habitando em si este espírito, isto é, que o homem é determinado em si para a suprema liberdade ${ }^{8}$.

É interessante o fato de que Hegel reconheça que nem mesmo a filosofia grega, nos seus mais altos expoentes (Platáo e Aristóteles), reconheceu que o homem é livre por natureza. C. Fabro esclarece que isso se deve ao intelectualismo da filosofia grega, que dava prioridade às essências abstratas e não ao singular concreto. Isso justificaria a posição privilegiada que os antigos filósofos reservavam ao intelecto na sua antropologia e foi utilizado para justificar doutrinas estranhas ao Cristianismo, como a da escravidão natural de certa parte da humanidade, defendida inclusive por Aristóteles?

\footnotetext{
${ }^{8}$ HEGEL, G. Enzyklopädie der philosophischen Wissenschaften, $\$ 482$; ed. Nicolin-Pöggeler, p. 388. Como bem nos lembra C. Fabro, Hegel afirmou também que somente nas naçóes germânicas o Cristianismo tomou consciência de que o homem é livre enquanto homem e que a liberdade do espírito constitui a sua mais própria natureza. Cfr. Philosophie der Geschichte; ed. Lasson, Bd. I, p. 39. FABRO, C. Riflessione sulla libertà, Rimini: Editrice del Verbo Incarnato, 1983. p. 23.

9 FABRO, C. Riflessioni sulla libertà, Rimini: Editrice del Verbo Incarnato, 1983, pg. 13: “Nell'intellettualismo greco, che preferisce l'universale astratto al singolare concreto, si può anche capire la posizione di privilegio riservata all'intelletto: anche per questo intellettualismo il mondo classico - e lo stesso Aristotele, com'è noto - ha difeso la
} 


\section{A liberdade segundo Santo Tomás de Aquino}

Em Santo Tomás de Aquino a noção de liberdade não é unívoca ou equívoca, mas sim análoga, ou seja, se refere a diversos tipos de realidades. É aplicada aos diversos entes espirituais, que possuem inteligência e vontade: Deus, os anjos e os homens. E ao mesmo tempo a própria liberdade humana apresenta uma diversidade de significados análogos. Pois pode se referir à liberdade de escolha ${ }^{10}$, também chamada de livre arbítrio ou liberdade psicológica pela tradição filosófica e teológica ${ }^{11}$; à liberdade moral (chamada de Libertas Major por Santo Agostinho) e a liberdade mais radical do ser humano, também chamada de "liberdade fundamental”, uma vez que se refere principalmente à abertura transcendental da inteligência e da vontade humanas à verdade e ao bem ${ }^{12}$. Veremos, pois, as características fundamentais da liberdade de escolha e depois trataremos da liberdade fundamental, que dá a razão de ser do livre arbítrio humano; por último trataremos a liberdade moral, ou seja, do sentido último da liberdade humana.

schiavitù come condizione naturale di una certa frazione dell'umanità. Questo è inammissibile, anche sul solo piano speculativo, dopo l'avvento del cristianesimo il quale insegna che la creazione è tutta opera di libertà e di amore, che attinge il fondo stesso della materia e quindi Dio conosce gli individui singolari come ammette espressamente anche $S$. Tommaso".

${ }^{10}$ De Veritate, q. 26, a. 6 c.: "Potentia qua libere iudicamus non intelligitur illa qua iudicamus simpliciter, quod est rationis, sed quae facit libertatem in iudicando, quod est voluntatis. Unde liberum arbitrium est ipsa voluntas: nominat enim eam non absolute sed in ordine ad aliquem actum eius qui est eligere".

${ }^{11}$ Um dos principais erros filosóficos sobre esse tema é a confusão entre a liberdade radical e o livre arbítrio. Carlos Cardona alertava contra esse perigo com as significativas palavras: "Es absolutamente falso concebir la libertad como la facultad de elegir entre el bien y el mal, que le solicitarian de modo contradictorio: sería tanto como afirmar que Dios no es libre, y que el hombre deja de serlo justamente en el momento en que ejercita su libertad. La libertad consiste en la facultad de querer, en el sentido fuerte del término. De ahi que todo ser dotado de inteligencia y voluntad sea libre, y que su libertad no sea algo distinto de su inteligencia y de su voluntad. Una perfecta libertad se dará, pues, en donde la inteligencia sea perfecta y sea perfecta la voluntad: en donde la Verdad y el Bien se den en perfecta identidad con el conocer y el querer". CARDONA, C. Libertad humana y fundamento. Consideraciones sobre el "ocaso de los valores" y la libertad de María Santísima, em «Scripta Theologica», 11 (1979), p. 1039.

${ }^{12}$ Cfr. MiLlÁN PUELLES, A. Economía y Libertad, conf. española de Cajas de Ahorro, Madrid 1974. 


\section{A liberdade de escolha (livre arbítrio)}

Santo Tomás trata esse assunto com profundidade nas Questôes Disputadas sobre a Verdade, questão vinte e quatro. Vejamos agora o que de fundamental foi afirmado em dita obra.

Em primeiro lugar podemos dizer que a liberdade de escolha implica duas dimensóes, uma negativa e uma positiva. Como dimensão negativa pode-se dizer que o livre arbítrio indica a ausência de constrição externa, nos atos tipicamente humanos. É a "liberdade de" coaçóes externas, constriçóes, ameaças externas, violência. A dimensáo positiva, por outro lado, manifesta que o homem é livre para fazer isso ou aquilo, para atuar ou não, ou seja, indica a diversidade de escolhas possíveis que se apresentam antes da realização de cada ato humano. Nesse sentido a liberdade de escolha indica a "liberdade para", ou a capacidade de autorealização que o ser humano tem nos seus atos.

Em De Veritate, q. 24 encontramos quinze artigos nos quais Santo Tomás trata a existência da liberdade segundo o seu significado analógico: no homem (art. 1), nos animais (art. 2) e em Deus (art. 3); a natureza do livre arbítrio humano, especialmente em relação com faculdade ativas (art. 4); também trata da questáo de se a liberdade está somente numa faculdade ou em várias (art.5) e se ela seja o mesmo que a vontade humana (art. 6). Os demais artigos (7-15) tratam de temas essencialmente teológicos.

Lemos no primeiro artigo daquela questáo que, sem a menor sombra de dúvidas o homem é livre. ("Absque omni dubitatione hominem arbitrio liberum ponere oportet".) E isso por três motivos: faz parte da fé cristã dita afirmação, pois, sem a qual, não seria possível nem o mérito, nem o demérito, nem o justo castigo ou o prêmio. Aqui podemos ver o diálogo constante da Filosofia com a Teologia nas obras de Tomás de Aquino; o segundo motivo é a experiência inconfundível de que o homem, ao escolher umas coisas, rejeita outras, o que é um indício claro de liberdade ("ad hoc etiam manifesta indicia inducunt, quibus apparet hominem libere unum eligere, et aliud refutare"). Esse aspecto da liberdade está de acordo com o aspecto fenomenológico da liberdade, apresentado, sobretudo, na modernidade; em terceiro lugar, as evidências anteriores nos permitem raciocinar e investigar a origem mesma da liberdade. (" $\mathrm{Ad}$ 
hoc etiam evidens ratio cogit, quam quidem ad investigationem liberi arbitrii originem sequentes, hoc modo procedemus.") E aqui tem, então, origem à investigação tipicamente metafísica, que procura reduzir os efeitos evidentes às suas causas últimas.

Santo Tomás então analisa os diversos tipos de movimentos naturais e os seus princípios, a partir de afirmaçóes tipicamente aristotélicas. De fato, no mundo inanimado, as realidades não se movem por si mesmas, como acontece entre os seres vivos, os quais operam segundo um juízo ínsito na sua própria natureza e ordenado a um resultado determinado. Ele dava então o exemplo das abelhas que produzem o mel e os pássaros que fazem seus ninhos sempre do mesmo modo. O homem, entretanto, age a partir de um juízo racional que consiste no conhecimento de algumas coisas como fins e de outras como meios em relaçáo a ditos fins. Desse modo, o homem aparece como ser livre, ao fazer dito juízo, e na atualização prática que segue ao juízo.

Aqui vemos algo próprio do ser humano: é o único ser capaz de distinguir entre meios e fins, de determiná-los, à diferença dos animais. O homem age de modo livre, não determinado ad unum, mas sempre pode agir de um modo ou de outro, agir ou não agir. $\mathrm{O}$ homem é, pois, senhor de seus atos livre e pode aceitar ou náo viver agir segundo os seus instintos.

Dito juízo é chamado por Santo Tomás de “juízo de eleição”, o qual é um juízo de tipo prático, não especulativo ${ }^{13}$. A escolha inclui, pois, dois elementos: o juízo e a sua execução. Tais elementos estão ordenados entre si. O principal deles é o juízo, pois como as açóes humanas são realizadas por meio de nosso corpo, pode ocorrer que, mesmo tendo decidido algo, não sejamos capazes de atuá-lo. Isso, no entanto, não nega o fato de sermos livres ${ }^{14}$.

Como conseqüência, Tomás afirma que a liberdade está primeiramente no modo de conhecer, ou seja, na capacidade de realizar juízos práticos e posteriormente na vontade

\footnotetext{
${ }^{13}$ De Veritate, q. 24 a. 1, ad 17: "Iudicium cui attribuitur libertas, est iudicium electionis; non autem iudicium quo sententiat homo de conclusionibus in scientiis speculativis; nam ipsa electio est quasi quaedam scientia de praeconsiliatis".

${ }_{14}$ De Veritate, q. 24 a. 2, ad 3: "In opere hominis duo est invenire: scilicet electionem operum, et haec semper in hominis potestate consistit; et operum gestionem sive executionem, et haec non semper in potestate hominis est, sed divina providentia gubernante, propositum hominis ad finem quandoque perducitur, quandoque vero non. Et ideo homo non dicitur esse liber suarum actionum, sed liber suae electionis, quae est iudicium de agendis" (Ib. ad 1). "Actiones, cum per corpus exerceantur, cogi possunt vel prohiberi, non solum in brutis, sed in hominibus, unde nec ipse homo dicitur liber actionis suae".
} 
humana e na efetiva realizaçáo do que foi decidido ${ }^{15}$. Desse modo, ele pôde afirmar com clareza: "totius libertatis radix est in ratione constituta", afirmação que criou certa suspeita de “intelectualismo" no Aquinate. Entretanto, ele fazia dita afirmação seguindo o ensinamento de Santo Agostinho e de São João Damasceno, como ele mesmo nos refere ${ }^{16}$.

Mais adiante o texto esclarece que o juízo prático é fundamental na liberdade de escolha por causa da capacidade reflexiva do intelecto ${ }^{17}$ (algo essencial também no conhecimento da verdade teórica) e porque o intelecto conhece as relaçóes entre as diversas realidades sobre as quais julga (discerne fins e meios) e pelas quais julga ${ }^{18}$.

Os animais, por outro lado, possuem capacidade de juízo, mas entretanto esse está sempre determinado ad unum, ou seja, a apetite e as açóes dos animais estáo sempre determinadas a agir de certo modo. E assim, Tomás afirma a realidade do livre arbítrio humano, diferenciando-o de algo análogo existente nos animais ${ }^{19}$.

\section{b) A liberdade fundamental}

15 De Veritate, q. 24 a. 2 c.: “Cum ad operationem nostram tria concurrant, scilicet cognitio, appetitus, et ipsa operatio, tota ratio libertatis ex modo cognitionis dependet".

${ }^{16}$ De Veritate, q. 24 a. 2 ad 4: "Causam autem liberi arbitrii assignat tam Damascenus quam Gregorius quam Augustinus rationem".

${ }^{17}$ Segundo Santo Tomás, o intelecto e a vontade são potências reflexivas, pois os atos dessas potências retornam sobre si mesmas e sobre os atos da outra. De Veritate, q. 22, a. 12 c.: "As potências superiores da alma, porque são imateriais, devem voltar sobre si mesmas. Por isso, seja a vontade, seja o intelecto retornam cada um sobre si mesmo e sobre a essência da alma e sobre todas as suas forças. O intelecto compreende a essência da alma e todas as suas faculdades e, de modo semelhante, a vontade quer o próprio querer e quer que o intelecto compreenda e quer a essência da alma e também todo o resto".

${ }^{18}$ De Veritate, q. 24 a. 2: "Iudicium autem est in potestate iudicantis secundum quod potest de suo iudicio iudicare: de eo enim quod est in nostra potestate, possumus iudicare. Indicare autem de iudicio suo est solius rationis, quae super actum suum reflectitur, et cognoscit habitudines rerum de quibus iudicat, et per quas iudicat: unde totius libertatis radix est in ratione constituta. Unde secundum quod aliquid se habet ad rationem, sic se habet ad liberum arbitrium. Ratio autem plene et perfecte invenitur solum in homine: unde in eo solum liberum arbitrium plenarie invenitur".

19 Ibidem: "Iudicium eorum est determinatum ad unum, per consequens et appetitus et actio ad unum determinatur; unde, secundum Augustinum, Lib. XI super Genes. Ad litteram, moventur visis; et secundum Damascenum, aguntur passionibus, quia scilicet naturaliter de tali viso et de tali passione sic iudicant; unde necesse habent ab ipsa visione alicuius rei vel a passione insurgente moveri ad fugiendum vel prosequendum, sicut ovis viso lupo necesse habet timere et fugere; et canis insurgente passione irae, necesse habet latrare, et prosequi ad nocendum. Sed homo non necessario movetur ab his quae sibi occurrunt, vel a passionibus insurgentibus quia potest ea accipere vel refugere; et ideo homo est liberi arbitrii, non autem bruta". 
Tratamos agora a liberdade humana no seu aspecto mais fundamental, enquanto que tem sua origem no ato de ser (actus essendi) da alma humana que, por sua vez, informa todas as faculdades e potências humanas. C. Fabro assim se referia a essa liberdade:

A liberdade tem uma infinidade de aplicaçōes e a partir da liberdade esta infinidade é comunicada à inteligência, à fantasia, à memória, à sensibilidade; é comunicada e realizada como se pode. E esta é a atitude existencial profunda e fundamental comum a todos os homens, não faz injustiça a nenhum homem ${ }^{20}$.

A liberdade fundamental é, pois, uma tarefa, uma exigência de responsabilidade, mas antes de tudo é um dom, fundada no mesmo ato de ser pessoal ${ }^{21}$.

Da leitura das questôes da Suma Teológica, nas quais Santo Tomás trata o tema da alma humana, podemos concluir que essa é forma do corpo, ou seja, é "o primeiro princípio da vida nos viventes"22 e é subsistente ("hoc aliquid"23), pois "comunica o ser no qual subsiste à matéria corporal e desta matéria e da forma se faz uma só entidade, de modo tal que o ser de todo o composto é também o ser da alma” ${ }^{24}$.

A doutrina tomista sobre a alma humana supóe toda sua metafísica, a qual se baseia na distinção real entre o ser (esse) e a essência (essentia), coisa que não era claro em Aristóteles. Desse modo, Santo Tomás pôde demonstrar que a alma humana, à diferença da alma dos animais, possui o ser por si mesmo e não está imersa na matéria. $\mathrm{O}$ actus essendi da alma humana é uma novidade no mundo natural e indica um modo de agir próprio, que se dá nas operaçóes de entender e querer espirituais. Nessas operaçóes vemos de modo patente à abertura da alma humana à totalidade do real, ou seja, ao ente enquanto verdadeiro e bom. As demais formas criadas estão imersas na matéria e suas açôes tem como sujeito (suppositum) o composto

\footnotetext{
${ }^{20}$ FABRO, C. Libro dell'esistenza e della libertà vagabonda, Asti: Piemme, 2000, aforisma n. 420.

${ }^{21}$ Ibidem, n. 474: "La libertà non è altro che il porsi in atto della libertà; io e libertà si appartengono come l'esterno e l'interno, come il concavo e il convesso, come il fuori e il dentro. Si appartengono necessariamente".

22 S.Th., I, q. 75 a. 1.

${ }^{23}$ S.Th., I, q. 75 a. 3.

${ }^{24}$ S.Th., I, q. 76, a. 1 , ad 5.
} 
de matéria e forma. As operaçóes de querer ${ }^{25}$ e de entender humanos têm como sujeitos a própria alma ${ }^{26}$. Por isso, C. Cardona disse que a inteligência e a vontade são a vida mesma da alma humana.

A inteligência e o amor são a atividade imanente da alma, são a sua vida. Essas duas faculdades, realmente distintas entre si, porque o são formalmente seus respectivos objetos (a verdade e o bem), são unidas na sua origem, que é a pessoa (as açôes pertencem aos próprios sujeitos), no ato humano (que é complexo, mas unitário: não pode dar-se um ato de pura razão, nem um ato de pura vontade; cada ato humano é ao mesmo tempo inteligente e voluntário) e no seu fim (porque a verdade é boa e o bem é verdadeiro) e especialmente no seu fim último, que é Deus (que é o Ser e a Verdade e o Bem e o Uno) ${ }^{27}$.

Desse modo, a autonomia operativa da alma se fundamenta na autonomia ontológica da mesma, uma vez que o agir segue o ser (agere sequitur esse). E a liberdade fundamental significa exatamente dita autonomia operativa da alma humana, manifestada no ato humano, ou seja, naquele ato realizado com o concurso da inteligência e da vontade.

${ }^{25}$ De Malo, 6, art. 1: "Se consideramos o movimento das potências da alma por parte do exercício do ato, assim o princípio do movimento pertence à vontade. Já que sempre aquela potência à que corresponde o fim principal, move ao seu ato à potência à que corresponde o que é para o fim ( ... ). Deste modo, a vontade se move a si mesma e a todas as outras potências. Entendo porque quero; e de modo semelhante, uso de todas as potências e de todos os hábitos porque quero".

${ }^{26}$ S. Th., I, q. 75, a. 2 c.: "Necessário é admitir-se que o princípio da operação intelectual, a que chamamos alma do homem, é um certo princípio incorpóreo e subsistente. Pois é manifesto que pela inteligência o homem pode conhecer a natureza de todos os corpos. Ora, o que pode conhecer certas causas, necessariamente não deve ter nada delas, na sua natureza, porque a causa que a esta fosse naturalmente inerente impedir-lhe-ia o conhecimento das outras. Assim, vemos que a língua do doente, afetada de humor colérico e amargo, nada pode sentir de doce, mas tudo lhe parece amargo. Se, pois, o princípio intelectual tivesse em si a natureza de algum corpo, náo poderia conhecer todos os corpos, porque cada corpo tem a sua natureza determinada. Logo, é impossível que o princípio intelectual seja corpo. E, semelhantemente, também é impossível que entenda por meio de órgão corpóreo, porque também a natureza determinada desse órgáo corpóreo impediria o conhecimento de todos os corpos. Assim, se uma determinada cor estivesse, não só na pupila, mas ainda num vaso de vidro, o líquido contido neste seria dessa mesma cor. Por onde, o princípio intelectual chamado alma ou intelecto tem a sua operação própria, não comum com o corpo. Ora, só pode operar por si o que por si subsiste, pois operar só é próprio do ser atual. Por isso, uma causa opera do mesmo modo pelo qual existe e, assim, não dizemos que o calor aquece, mas que é quente. Logo, conclui-se que a alma humana, chamada intelecto ou mente, é algo de incorpóreo e subsistente”.

${ }^{27}$ CARDONA, C. Metafisica del bene e del male, Ares, Milano 1991, pg. 113. E continuava, citando C. Fabro: "É o fim e o bem que domina (e deve dominar) a vida do espírito: o fundamento, de acordo, é a apreensão do ensverum, mas a dinâmica concreta é sob a guia da vontade, que tem por objeto o bonum e também por isso se diz que finis é primum in intentionem e ultimum in executionem et assecutione" (Fabro, C. Riflessione sulla libertà.., pg. 30). 
A alma humana é, pois, princípio de vida, que informa todo o corpo e todas as potências espirituais, mas não é um princípio absoluto, como é a vida divina, pois está de certo modo predeterminada a agir segundo a luz dos primeiros princípios do real e segundo a tendência da vontade ao fim último. Assim afirma Santo Tomás:

Embora, porém, o nosso intelecto se mova por si mesmo a agir, contudo, certas condiçôes lhe são impostas pela natureza, como os primeiros princípios, que ele não pode deixar de admitir, e o último fim, que não pode deixar de querer. Donde, embora sob certos aspectos, move-se a si mesmo, a outros, contudo, é necessário que seja movido por outro. Mas o ser, cuja natureza é o seu próprio entender, e que não recebe de outro o que naturalmente tem, este desfruta o sumo grau da vida. E tal é Deus. Logo, em Deus existe por excelência a vida. Por isso o Filósofo, tendo demonstrado que Deus é inteligente, conclui, que tem vida perfeitíssima e sempiterna, porque o seu intelecto é perfeitíssimo e sempre atual ${ }^{28}$.

\section{c) A liberdade moral}

A liberdade humana, pois, é real, mas não é absoluta como a divina, pois é a liberdade de um ser criado e limitado. Além disso, a liberdade é a característica principal da nossa alma, síntese de todas as suas possibilidades. C. Fabro dizia que "a liberdade é a qualidade originária do espírito e o espírito enquanto espírito é a emergência absoluta sobre o particular. $\mathrm{O}$ espírito é um absoluto temporal, um absoluto existencial" ${ }^{29}$. Essa liberdade fundamental humana é, pois, participação na perfeição divina, de modo que somente quando está em harmonia com dita perfeição pode alcançar seu fim próprio. A liberdade é fruto da liberalidade divina, que com amor de benevolência criou o homem livremente. E o criou justamente para ser livre, amando.

Se a liberdade é o atributo mais profundo que nos assemelha a Deus, se Cristo veio na Terra por um ato de liberdade e de amor, a sua fórmula radical não é a inteligência, mas o amor. Somente em nível de amor se restitui a igualdade originária ${ }^{30}$.

\footnotetext{
${ }^{28}$ S. Th.,I, q. 18 , a. 3 c.

${ }^{29}$ FABRO, C. Libro dell'esistenza e della libertà vagabonda..., cit., n. 440.

${ }^{30}$ Ibidem, n. 419.
} 
Em De Veritate q. 22 Santo Tomás distingue claramente a liberdade moral, chamada entáo de "libertas a peccato et a miseria", e a liberdade de eleição ou psicológica: "libertas a coactione". A liberdade moral pode crescer ou diminuir, segundo o sujeito realize atos humanos bons ou maus. A liberdade psicológica não pode, por outro lado, crescer ou diminuir, a não ser em casos patológicos ${ }^{31}$.

No artigo quinto daquela questão Santo Tomás se interrogava se a vontade quer algo por necessidade. Respondia distinguindo uma dupla necessidade: a de coação e a de inclinação. E afirmava que a vontade quer algo por necessidade de inclinaçáo natural: a felicidade e os bens diretamente relacionados com essa: a bem-aventurança, o ser, o conhecimento da verdade etc.; não pode, entretanto, querer algo por necessidade de coação, algo que contrariaria a sua mesma natureza.

Logo em seguida afirmava que nas realidades ordenadas, o que é primeiro está incluído no segundo e que se encontra no segundo não só aquilo que lhe compete por uma razão própria, mas também o que lhe compete segundo a razão do primeiro. $\mathrm{O}$ exemplo que dá Santo Tomás é o tato, que está presente em todos os sentidos, e por isso é o fundamento de todos eles.

De modo semelhante, natureza e vontade estão ordenadas, pois a vontade é certa natureza (voluntas ut natura), uma vez que tudo o que se encontra nas coisas é certa natureza. Sendo assim, na vontade encontramos não somente aquilo que é próprio da vontade, mas também algo que é próprio à natureza. E o que se dá em toda natureza criada é sua ordenação (dada por Deus) ao bem, que lhe faz desejar-lhe naturalmente. Por isso, certo apetite natural do bem conveniente está inerente na mesma vontade. Isso nos mostra a intrínseca ordenação da vontade ao fim último, algo central na moral tomista. Dita ordenação se relaciona com o intelecto como uma relação de proporcionalidade: a voluntas ut natura está para a vontade de eleição (o livre arbítrio) assim como o intelecto está para a razão teórica ${ }^{32}$.

${ }^{31}$ De Veritate, q. 22 a. 5 ad 14: "Libertas quae augetur et minuitur, est libertas a peccato et a miseria, non autem libertas a coactione".

32 S. Th., I, q. 83, a. 4 c.: "Do mesmo modo se encontra no intelecto o princípio em relação à conclusão, à que assentimos pelos princípios, que na potência apetitiva o fim em relaçáo dessas coisas que visam ao fim, que se 
Além disso, a vontade se determina a outras coisas - que não são o fim último - não por inclinação natural, mas por própria disposição, sem nenhuma necessidade, uma vez que há bens particulares que possuem uma relação necessária com a felicidade e outros, não ${ }^{33}$. Se, pois, a voluntas ut natura está intimamente relacionada com a inclinação ao fim último, a voluntas ut ratio se refere aos meios com os quais se busca a felicidade.

E no artigo sexto daquela questão (q. 22) Santo Tomás diz que a vontade tem também indeterminação respeito do objeto, do ato e da sua ordem ao fim: a) quanto ao objeto de volição a vontade é indeterminada com relação aos meios ("ea quae sunt ad finem"), não em relação ao fim último, pois para se chegar ao fim último existem muitas vias. Por isso a vontade humana náo pode estar determinada em relação aos meios, como acontece entre os animais, determinados ad unum (também em relação aos seus meios); b) enquanto ao seu ato, a vontade é indeterminada porque pode querer ou náo querer ${ }^{34}$; c) e quanto à ordem ao fim, a vontade é indeterminada porque pode querer o fim último verdadeiro ou um fim só aparentemente verdadeiro ${ }^{35}$.

E esta última indeterminação provém do fato de que nosso conhecimento pode ser errôneo, pode basear-se numa falsa apreensão. ("Ex indeterminatione apprehensionis, quae potest esse recta vel non recta.") Entretanto, se há um apetite reto do fim, não poderia haver uma volição desordenada, a não ser que a razão considerasse certo ato (um ato particular no momento em que é praticado) ordenável ao fim, quando na verdade este não o é $e^{36}$. Sendo assim, somente se pode desejar de modo desordenado, ou seja, só se pode querer um pecado, se

apetecem pelo fim. Portanto, é manifesto que tal como se encontra o intelecto em relação à razão, assim se encontra a vontade em relaçáo à potência eletiva, ou seja, o livre arbítrio”.

${ }^{33}$ Cfr.: S. Th., I, q. 82, a. 2 c.

${ }^{34}$ De Veritate, q. 22, a. 6 c.: "Secundo est voluntas indeterminata etiam respectu actus; quia etiam circa obiectum determinatum potest uti actu suo cum voluerit, vel non uti; potest enim exire in actum volendi respectu cuiuslibet, vel non exire".

35 Ibidem: "Indeterminatio voluntatis est respectu ordinis ad finem, in quantum voluntas potest appetere id quod secundum veritatem in finem debitum ordinatur, vel quod secundum apparentiam tantum".

${ }^{36}$ Ibidem: "Ex quo inest appetitus rectus ultimi finis, non posset sequi quod aliquis inordinate aliquid appeteret, nisi ratio acciperet aliquid ut ordinabile in finem quod non est in finem ordinabile". 
dita ação é apreendida como certo bem, pois pode parecer com algo que causa prazer ou como ordenável à felicidade ${ }^{37}$.

De modo que somente a partir do caráter limitado da nossa vontade, principalmente por causa da sua indeterminação em relaçáo ao fim último, se explica que a vontade possa querer o bem ou o mal. ("Et ex hoc sequitur indeterminatio voluntatis, qua potest bonum vel malum appetere.")

Num texto anterior ao De Veritate, Santo Tomás explica essa falibilidade da nossa vontade com interessantes palavras, que manifestam que nossa vontade é livre quanto à determinaçáo do ato particular, que pode diferir da ordem que a pessoa deu à sua vida em relação ao fim ultimo universal (pela voluntas ut natura), uma vez que os atos da vontade $u t$ ratio são sempre particulares.

Se considerarmos o movimento da vontade por parte do objeto que determina o ato da vontade a querer isto ou aquilo, há que levar em conta que o objeto que move a vontade é o bem conveniente apreendido como tal. De maneira que se um bem é apreendido como bem, mas náo como conveniente, não moverá a vontade. Sendo assim, como quer que o conselho e a eleição versem sobre o particular, sobre o que versa também o ato, se requer que o apreendido como bom e conveniente, o seja como bom e conveniente em particular e náo só como universal. Se se apreende algo como bom ou conveniente segundo todos os elementos que constituem a particularidade, tal como pode ser conhecida, necessariamente moverá a vontade: de aí que o homem necessariamente queira a felicidade que, segundo Boécio (liv. III De Consol., prosa 2), é o estado perfeito de congregaçáo de todos os bens. Mas digo necessariamente enquanto à determinação do ato, já que pode alguém não querer então pensar na felicidade porquanto os atos mesmos do intelecto e da vontade são particulares $^{38}$.

E no De Veritate, Tomás esclarece que a possibilidade de pecar, ou seja, a falibilidade da vontade humana é um sinal da liberdade, mas não sua perfeição. O essencial da liberdade é o domínio sobre os próprios atos e não a sua falibilidade.

37 Ibidem: "Sicut qui appetit naturaliter beatitudinem appetitu recto, nunquam deduceretur in appetendam fornicationem, nisi in quantum apprehendit eam ut quoddam hominis bonum, in quantum est quiddam delectabile, et sic ut ordinabilem in beatitudinem, velut quamdam imaginem eius".

${ }^{38}$ In II Sent., d. 39, q. 1, a. 1 c. 
Poder pecar não é parte da liberdade; não se requer para que a vontade seja livre o que possa cair em pecado, pois basta à razão de liberdade o domínio sobre os próprios atos. Mas este domínio, nos que podem pecar, implica que pequem livremente, já que é a mesma vontade aquela com que se peca e com que se vive retamente ${ }^{39}$.

Em outras palavras, "querer o mal não é liberdade nem parte da liberdade, ainda que seja um signo da liberdade" ${ }^{40}$; “a vontade é libérrima e ninguém a pode sujeitar à escravidão; mas ela pode fazer-se escrava se livremente consente ao pecado" ${ }^{41}$.

O pecado é, pois, um sinal da liberdade, mas não sua perfeição, não seu objetivo último. A liberdade é fruto do amor divino e o seu fim é o mesmo amor. Por isso a liberdade é tão difícil de ser entendida e explicada, assim como o amor.

A liberdade radical não é simplesmente a conclusão das promessas objetivas do intelecto, mas é a conclusão da promessa subjetiva do amor; eu arisco porque amo, quero arriscar porque amo; e por que amo? Do amor não há um porquê. E é nesse momento da vontade que só a liberdade pode fazer que se realize o "salto" da fét2.

A liberdade humana se fundamenta no próprio ato de ser pessoal, que foi concedido ao homem por um gesto de liberalidade divina: a criação. Desse modo, o princípio da liberdade é também o fim último da mesma. O homem é livre porque foi criado por amor e é livre para amar, para doar-se com liberalidade. Pode-se dizer que o sentido último da liberdade é o amor de amizade. Tal explicação última da liberdade se deve ao Cristianismo e é uma tarefa dos cristáos, também nos nossos dias, levar tal mensagem de alegria e de esperança a todos os homens.

\footnotetext{
${ }^{39}$ In II Sent., d. 44, q. 1, a. 1 ad 1.

${ }^{40}$ De Veritate, q. 22, a. 6 c.

${ }^{41}$ De Malo, q. 1, a. 5

${ }^{42}$ FABRO,C. Libro dell'esistenza e della libertà vagabonda ..., cit., n. 424.
} 


\section{Conclusão}

A liberdade entendida exclusivamente como mera capacidade de eleição (“libertas a coactione") é um modo correto de se explicar a liberdade, mas é apenas um dos seus aspectos mais superficiais. A liberdade significa efetivamente domínio sobre os próprios atos, ausência de constriçáo, mas tal capacidade deve haver um porquê. A filosofia moderna tende a se contentar com o aspecto fenomenológico da liberdade (com a consciência da liberdade ou com a experiência da mesma), mas não entra a fundo na sua explicação.

A liberdade de eleição tem sua razão no ato de ser humano, que informa todas as suas capacidades, principalmente as potências superiores. Dito ato de ser é a grande descoberta da filosofia de Santo Tomás de Aquino e nos ajuda a compreender também a esse difícil e apaixonante tema filosófico: a liberdade humana.

O ato de ser humano é único, uma novidade radical, que diferencia o homem dos animais e dos demais entes criados desprovidos de razáo e se manifesta na possibilidade da vontade humana determinar o seu fim último e os meios com os quais pretende alcança-lo.

A modernidade produziu uma enorme reduçáo no conceito de liberdade, ainda que tenha discutido abundantemente sobre o tema. De modo que se pode dizer que se a liberdade é entendida somente como a capacidade de escolha de meios, sem que haja um autêntico fim, resulta que todas as escolhas humanas se tornam indiferentes e pode parecer lógica a afirmação de que "o homem é condenado a ser livre" 43 (Sartre).

Se a liberdade é uma conquista que a civilização ocidental deve ao Cristianismo ${ }^{44}$, tal como afirmava Hegel, podemos dizer que a redescoberta do seu sentido também é tarefa urgente dos cristãos e dos filósofos que buscam as causas últimas de todas as coisas.

\footnotetext{
${ }^{43}$ SARTRE, J.-P. L'existetialisme est un humanisme, Paris: Nagel 1948, p. 37.

${ }^{44}$ HEGEL, G. Geschichte der Philosophie; ed. Michelet, Berlin 1840, Teil I, p. 63: "Certamente o sujeito era indivíduo livre, mas se sabia tal somente na unidade com a própria essência: o ateniense se reconhecia como livre somente como ateniense e do mesmo modo o cidadáo romano como ingenuus. Mas que o homem fosse livre em si e por si, segundo a própria substancia, que fosse nascido livre como homem, isso não soube nem Platão, nem Aristóteles, nem Cícero e nem menos os juristas romanos, ainda que esse conceito seja a fonte do direito. No princípio cristão por primeira vez o espírito individual pessoal é essencialmente de valor infinito, absoluto; Deus quer que todos os homens sejam ajudados".
} 
A liberdade tem pois seu fundamento no actus essendi humano que por sua vez è causado e participa no ser divino. Essa é um dom de amor do Criador e encontra seu fim somente no retorno do homem ao seu princípio último, pelo amor. Segundo Santo Tomás, do seu amor dominante cada homem recebe sua qualificaçáo moral, ou seja, como bom ou mal. O homem foi criado por amor e somente se ama sua causa última se realiza como pessoa.

O amor é o primeiro ato da liberdade, tanto em Deus ao criar o mundo (sua primeira obra ad extra) assim como no homem. De fato, em S.Th. I-II, q.89, a.6, Tomás de Aquino afirma que o início da vida propriamente moral se dá quando por primeira vez o homem escolhe entre amar a Deus sobre todas as coisas ou a si mesmo, de modo que esse ato primeiro pode ser considerado como a raiz de toda a vida moral humana.

Sendo assim, podemos concluir dizendo que a liberdade é a forma última do ato de ser próprio do homem, que informa todas as suas açóes, ou seja, tudo aquilo que é realizado por ele, contando com a participação dos seus princípios intelectuais e volitivos. A liberdade radical está fundada no mesmo actus essendi da alma humana e se manifesta nos atos humanos realizados com suas faculdades superiores: a inteligência e a vontade. Tal liberdade é participada, limitada e se dirige a um fim: a autodoação de si mesmo, à imitação da liberalidade divina. 


\section{Referências Bibliográficas}

TOMÁS DE AQUINO. Corpus Thomisticum: S. Thomae Aquino Opera Omnia. Fundación Tomás de Aquino, 2000-2011. Disponível em: <http://www.corpusthomisticum.org/iopera. html . Acesso em: 01 set. 2011.

BROCK, S. Tommaso d'Aquino e lo statuto fisico dell'anima spirituale. L'Anima. Annuario di Filosofia 2004. Milano: Mondadori, 2004, 67-87; 323-326.

CARDONA, C. Libertad humana y fundamento. Consideraciones sobre el "ocaso de los valores” y la libertad de María Santísima. Scripta Theologica, 1979, 11, pp. 1037-1055. . Metafisica del bene e del male. Milano: Ares, 1991.

CLAVELL, L. Metafísica e Libertà. Roma: Armando, 1996.

FABRO, C. Libro dell'esistenza e della libertà vagabonda. Asti: Piemme, 2000. . Riflessioni sulla libertà. Rimini: Editrice del Verbo Incarnato, 1983.

HEGEL, G. Geschichte der Philosophie. Berlin: Ed. Michelet, 1840. Enzyklopädie der philosophischen Wissenschaften. Hamburgo: Ed. Nicolin-Pöggeler, 1959.

RUSSO-J. VILLANUEVA, F. Le dimensioni della libertà. Roma: Armando, 1995.

SARTRE, J.-P. L'existetialisme est un humanisme. Paris: Nagel 1948.

YEPES, R., ARANGUREN, J. Fundamentos de Antropologia: um ideal da excelência humana. Trad. P. Dwyer. Sáo Paulo: Instituto Brasileiro de Filosofia e Ciência "Raimundo Lúlio", 2005. 